\title{
Integração de dados de decaimento radiométrico de urânio: estudo de caso na região de Santa Maria (RS)
}

\author{
João Eduardo Pereira ${ }^{1}$, José Luiz Silvério da Silva ${ }^{1}$, Adelir José Strieder ${ }^{2}$ \& Carlos Alberto Pires ${ }^{1}$
}

\begin{abstract}
Resumo O presente trabalho trata da integração de dados de concentrações do elemento urânio, em partes por milhão (ppm), associadas as diferentes formações rochosas pertencentes à Bacia do Paraná na região de Santa Maria no Estado do Rio Grande do Sul. Desenvolvido a partir de dados primários gerados pela Companhia de Pesquisas e Recursos Minerais parte do Projeto AERO/Camaquã, código de série 1010, digitalizadas no formato XYZ Geosoft 1997. Através de uma malha irregular de valores de concentração de urânio, totalizando 25806 observações, referenciadas espacialmente em coordenadas UTM que variaram de Oeste para Leste desde 206190 até 276813 E e de Norte para Sul desde 6670888 até 6735665 N, perfazendo uma área de $4574,75 \mathrm{~km}^{2}$. Com o emprego suporte computacional Statística 7.1, licenciado para o Departamento de Estatística da Universidade Federal de Santa Maria. Estimou-se os valores de médias e os limites de confiança a $\alpha=0,05$, os desvio padrões, das concentrações de urânio para cada formação rochosa, as comparações entre os valores médios através do Teste de Tuckey e a variação espacial das concentrações em função das coordenadas geográficas foram ajustadas a um modelo polinomial. A partir dos resultados obtidos mostrou-se que as concentrações de urânio ocorrem de forma distinta nas diferentes formações geológicas estudadas (sedimentos inconsolidados aluvionares, arenitos e rochas ígneas vulcânicas ácidas e básicas). A variável urânio quando espacializada em função das coordenadas geográficas ajustou-se a um modelo polinomial de segunda ordem.
\end{abstract}

Palavras-chave: integração de dados, estatística, SIG.

\begin{abstract}
Data integration from gamma radiation decaiment from uranium: a case-study in the region of Santa Maria, Rio Grande do Sul-Brazil. This work consists of data integration of uranium concentrations, parts per million (ppm), associated to the different rock formations belonging to Paraná Basin in the region of Santa Maria, in the Rio Grande do Sul state southern Brazil. This study was developed from primary data generated by the Companhia de Pesquisas de Recursos Minerais as part of the AERO/Camaquã; Project, 1010 code series, digitalized in the 1997 Geosoft XYZ format. Through an irregular net of values of uranium concentration, with 25806 observations were spatially oriented by Universal Transverse Mercator/ UTM coordinates. Which were varied from west to east 206190 to $276813 \mathrm{E}$, and from north to south 6670888 to $6735665 \mathrm{~N}$, totalizing an area of $4574.75 \mathrm{~km}^{2}$. Using Statistica 7.1 software licensed to the Department of Statistics at the Federal University of Santa Maria, the mean values of and the confidence limits with $\alpha=0.05$, the standard deviations of uranium concentrations for each rock formation. The comparisons between the mean values were made through the Tuckey's Test and the spatial variation of the concentrations in relation to the geographical coordinates were adjusted to a polynomial model. The results obtained showed that the uranium concentrations occur in a distinct way in the different geological formations studied (aluvionar unconsolitaded sediments, sandstones and igneous volcanic acid and basic rocks). The uranium variable, when spatialized in relation to the geographical coordinates UTM were adjusted to a second order polynomial model.
\end{abstract}

Keywords: data integration, statistics, GIS.

INTRODUÇÃO Na área de geociências a integração de dados é um procedimento comum. Na década de 70 , ainda a integração era basicamente visual e a quantidade de informações utilizadas eram reduzidas, pois todo o processo de integração e análise dos resultados era desenvolvido pelo pesquisador. Assim, o resultado final obtido era, principalmente, da experiência e da capacidade de observação do pesquisador e ainda a metodologia utilizada possuía características pessoais. Já nos anos 80, em alguns países, a integração de dados começou a ser feita com o auxílio de sistemas computacionais. Alguns trabalhos que exemplificam este novo procedimento de integração de dados geológicos foram os de Eliason et al. (1983), Green \& Craig (1984) e Aarnisalo (1984) dentre vários outros.

Assim, sistemas e algoritmos computacionais começaram a ser desenvolvidos para tratar e analisar grande volume de informações e processar a diversidade de dados obtidos por diferentes tipos de sensores. Com estes recursos foi possível utilizar-se técnicas de geopro-

1 - Universidade Federal de Santa Maria, Centro de Ciências Naturais e Exatas, Departamento de Geociências, Santa Maria (RS), Brasil.

E-mail: jesp61@gmail.com, silverio@smail.ufsm.br, calpires@base.ufsm.br

2 - Universidade Federal do Rio Grande do Sul, Departamento de Engenharia de Minas, Porto Alegre (RS), Brasil. E-mail: adelir@ufrgs.br 
cessamento para trabalhar conjuntamente com informações geofísicas, imagens de satélite e radar, entre outras.

No Brasil, os trabalhos pioneiros com esse novo sistema foram os de Paradella et al. (1990), Rolim (1992 in Rolim et al. 1993), Almeida Filho \& Castelo Branco (1992), Miranda et al. (1992), entre outros.

Segundo Bastos (2002) a gamaespectrometria consiste na detecção dos raios gama emitido pelos isótopos radioativo presentes na superfície do terreno visando à estimativa da quantidade dos mesmos. Os radioelementos naturais mais abundantes na superfície terrestre são o potássio, o tório e o urânio. O urânio é detectado pela medida dos raios gama de energia 1,76 Mev emitido pelo decaimento do ${ }^{214} \mathrm{Bi}$.

A técnica de aerogamaespectrometria consiste em medir a produção de raios gama que são emitidos no decaimento dos elementos radioativos (Wilford et al. 1997).

Com essa finalidade, em 1995 a Companhia de Pesquisas de Recursos Minerais (CPRM) criou o Projeto AERO, com o intuito de fornecer informações técnicas sobre todas as fases dos principais levantamentos aerogeofísicos executados no Brasil desde 1952. A divisão de geofísica da CPRM possui em seus bancos de dados, sob o código de série 1010, o Projeto Camaquã que contém dados da Região Central do Estado do Rio Grande do Sul. Os dados fornecem informações sobre os níveis de magnetometria (Mag.), Contagem Total de emissões radioativas (CT), emissões radioativas de potássio (K), emissões radioativas de tório (Th) e emissões radioativas de urânio $(\mathrm{U})$, georeferenciados em Sistema de Informações Geográficas/SIG através do sistema de coordenadas Universal Transversa de Mercator (UTM) Buffon (2002).

Este estudo de caso realizado na região de Santa Maria teve por objetivo desenvolver uma integração entre os dados de radiação Gama, parâmetros para urânio, na faixa entre 1,66 e 1,86 Mev do Projeto Camaquã, código de série 1010, pertencente ao projeto AERO. Este projeto foi criado pela Companhia de Pesquisas de Recursos Minerais, em 1995, sob a administração da Divisão de Geofísica, localizada na região central do Estado do Rio Grande do e Sul.

As unidades geológicas aflorantes na Região de Santa Maria fazem parte da Província Paraná (Favilla \& Caldasso 1998, CPRM 2008), compreendem a Formação do Rio do Rasto (sedimentar clástica, constituída por pelitos e arenitos, com dominância de camadas tabulares ou lentificulares muito estendidas de paleoambientes: lacustre, eólico, deltáico e raros depósitos fluviais) pertencente ao Grupo Passa Dois, de Idade Permiana. O Grupo Rosário do Sul (sedimentares clásticas constituídas por corpos tabulares ou lenticulares alongados, com brecha e conglomerado intraformacional, siltito e raro argilito, de ambiente continental de canal entrelaçado, com arenitos grossos a conglomeráticos, com pelitos subordinados de cores vermelha) com calcretes Silvério da Silva (1997). $\mathrm{Na}$ escala deste trabalho não foram separadas as formações (Rosário do Sul= Sanga do Cabral, Santa Maria (Membro Passo das Tropas e Membro Alemoa)) nem a
Formação Caturrita. A Formação Botucatu constitui-se de um arenito fino a grosso, com grãos bem arredondados, com alta esfericidade, dispostos em sets e/ou cosets de estratificação cruzada de grande porte, de paleoambiente continental desértico, constituídos por depósitos de dunas eólicas do Período Jurássico. A Formação Serra Geral pertencente ao Grupo São Bento, de Idade Cretácea é constituída por derrames de rochas vulcânicas; subtipo ácidas $\left(\alpha_{1}\right)$ de composição intermediária a ácida, variando entre andesitos e riodacitos. As rochas básicas $\left(\beta_{1}\right)$ são constituídas por derrames basálticos granulares finos a médios, melanocráticos cinza, com horizontes vesiculares e intercalações com arenitos intertrápicos Botucatu, pertencente ao Período Cretáceo.

Por outro lado os sedimentos inconsolidados da Era Cenozóica, Período Neógeno, pertencem aos Depósitos associados as barreiras holocênicas: Depósitos Aluviais: constituídos por areia grossa a fina, cascalho e sedimentos síltico-argilosos, depositados em calha de rio e planícies de inundação. Nesta pesquisa foram considerados depósitos aluviais atuais (Favilla \& Caldasso 1998, CPRM 2008).

Geomorfologicamente este pacote litológico pertence à borda da Bacia do Paraná, enquanto as rochas sedimentares clásticas de idade variando entre Permiano ao Neógeno (Holoceno) pertencem a Depressão Periférica Müller Filho (1970), as rochas vulcânicas pertencem ao Rebordo do Planalto da Serra Geral.

MATERIAIS E MÉTODOS O presente estudo caracteriza-se como sendo uma pesquisa de cunho quantitativo. Conforme Richardson apud Cruz \& Remacre (2001), as pesquisas de natureza quantitativa demonstram a intenção de garantir a precisão dos resultados, evitando distorções de análise e de interpretação, e ainda, possibilitam uma margem de segurança quanto às interferências. De acordo com Landim (2000) o estudo quantitativo pode gerar questões para serem aprofundadas qualitativamente, e vice-versa.

A base de dados de Projetos Aerogeofísicos do Brasil, denominada AERO, foi criada pela Companhia de Pesquisa de Recursos Minerais em 1995. Seu principal objetivo foi prover o usuário de informações técnicas sobre todas as fases dos principais levantamentos aerogeofísicos executados no Brasil desde 1952. Tendo em vista os diferentes patrocinadores desses projetos e procurando evitar superposições de áreas, cada projeto pertencente a um patrocinador, por isso foram agrupados e numerados por códigos como: 1000, 2000, 3000 e 4000, apresentando-se em ordem crescente segundo o ano do levantamento, situando-se em mapas com localização individuais, de acordo com seus patrocinadores. Os códigos da série e seus patrocinadores são: (a) Códigos da Série 1000 - projetos conduzidos pelo Departamento Nacional de Produção Mineral (DNPM) e Companhia de Pesquisa de Recursos Minerais/ CPRM - Serviço Geológico do Brasil; (b) Códigos da Série 2000 - projetos conduzidos pela Comissão Nacional de Energia Nuclear (CNEN) e pela Empresas Nucleares Brasileiras S.A. (NUCLEBRÁS); (c) Códigos da Série 
3000 - projetos conduzidos pelos governos estaduais e empresas privadas; (d) Códigos da Série 4000 - projetos conduzidos pelo Conselho Nacional do Petróleo (CNP) e pela Petróleo Brasileiro S.A. (PETROBRAS, Centro de Pesquisa de Recursos Minerais, 2005).

O Projeto Camaquã (Área II) abrange a Serra do Jaraú, situada a oeste da Área I do projeto e a sudoeste do estado do Rio Grande do Sul. Esta área foi requerida pelo Departamento Nacional de Pesquisa de Mineração (DNPM).

A Divisão de Geofísica-DIGEOF/DEGEO da (CPRM) digitou os dados magnéticos e gamaespectrométricos do projeto a partir das listagens de computador, bem como a digitalização das coordenadas geográficas/UTM das fiduciais dos perfis com a finalidade de compor o "arquivo de dados XYZ" do projeto. Dessa forma, todo o Projeto Camaquã (Área I) teve seus dados digitados novamente sob a forma de "arquivo XYZ" (formato Geosoft), em 1997.

Tratamento dos Dados Esta pesquisa encontra-se em fase de desenvolvimento como parte da tese de doutoramento do primeiro autor tendo como contribuições Pereira (inédito) e Pereira et al. (2007 e 2008). Os dados radiométricos aqui utilizados foram convertidos de "contagens por segundo" (cps) para concentração de elementos: percentagem (\%) para k, parte por milhão (ppm) para equivalente urânio (eU), equivalente tório (eTh) e Microroentgen por hora para o Canal de Contagem Total, a partir da técnica denominada de "back-calibration". Tal técnica foi transferida para a CPRM através do projeto Brazil Airborne Radiometric Mapping Project (BARMP), de acordo com o Convênio de Cooperação Técnica celebrado em 17/10/1996 entre esta e o Geological Survey of Canada (GSC). Contou ainda com a participação da empresa canadense de consultoria em Geofísica Paterson, Grant \& Watson Limited (PGW), com o apoio financeiro da Canadian International De- velopment Agency (CIDA) - Project Number 204/13886 - Canada-Brazil Cooperation Project for Sustainable Development in the Minerals Sector (CPRM/GSC/PGW 1997). Os principais parâmetros do projeto Camaquã (CPRM 2007) estão ilustrados no tabela 1.

Tabela 1 - Principais parâmetros do projeto Camaquã (CPRM 2007).

\begin{tabular}{l|l}
\hline Parâmetros & Unidades \\
\hline Intervalo de amostragem & 1 segundo \\
\hline Altura de vôo & 150 metros \\
\hline $\begin{array}{l}\text { Direção e espaçamento das linhas } \\
\text { de vôo (LV) }\end{array}$ & NW-SE, 1 Km \\
\hline $\begin{array}{l}\text { Direção e espaçamento das linhas } \\
\text { de controle (LC) }\end{array}$ & NE-SW, 18 Km \\
\hline Tempo de integração gama & 2 segundos \\
\hline Cristais de NaI (TI) & 2491,59 pol. cúblicos \\
\hline
\end{tabular}

A localização da área de estudo abrange a Folha de Santa Maria, no Estado do Rio Grande do Sul, na escala de 1: 250.000 entre as coordenadas $29^{\circ} 00^{\prime}$ a $30^{\circ} 00^{\prime}$

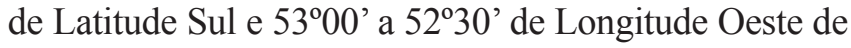
Greenwich, Folha SH 22-V.C. Para reconhecimento das formações geológicas no terreno fez-se uso do posicionamento através do Global Position System/GPS Garmin Etrex. Utilizaram-se as coordenadas em projeção Universal Transversa de Mercator/UTM, com uso do datum horizontal SAD 69 e datum vertical o Porto de Imbituba em Santa Catarina, equivalentes a UTM que variaram de Oeste para Leste desde 206190 até 276813 E e de Norte para Sul desde 6670888 até 6735665 N.

A figura 1 ilustra o mapa geológico da região

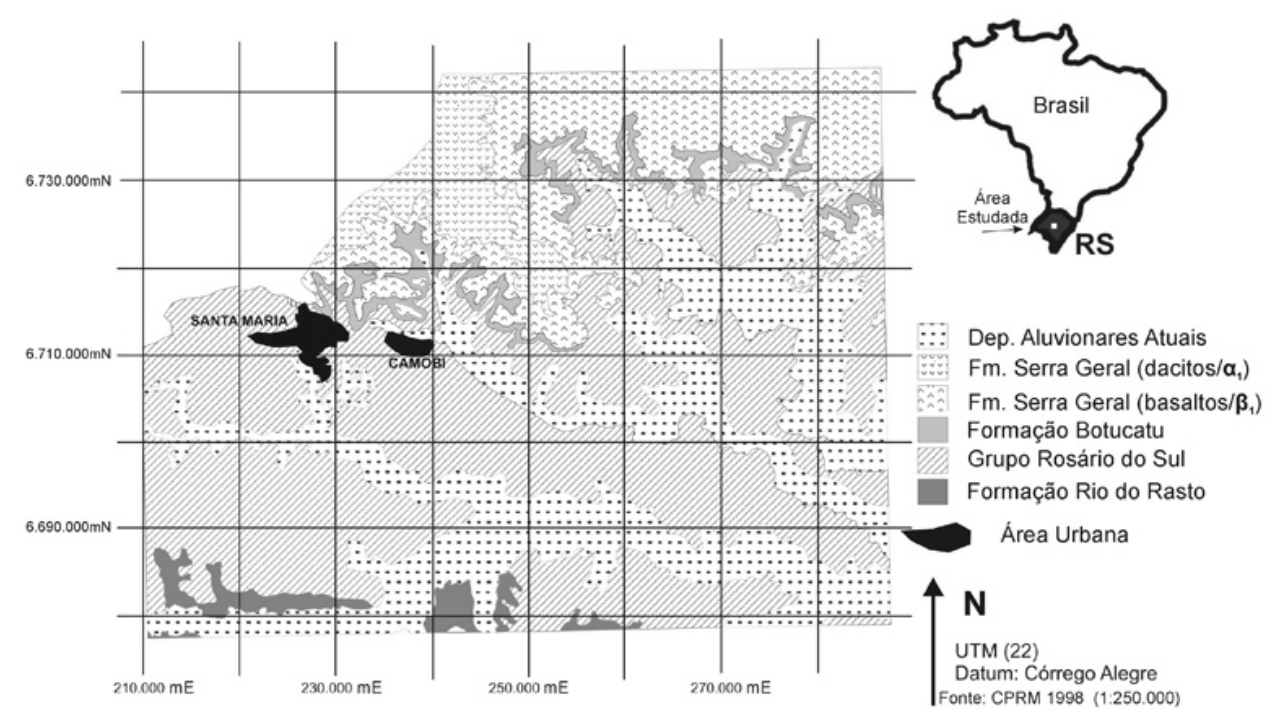

Figura 1-Mapa da região de abrangência do estudo Folha Santa Maria 1:250.000. UTM Datum Horizontal SAD-69. Fonte: Favilla e Caldasso (1998). 
de abrangência da área de estudo, situada na na Borda da Bacia do Paraná entre o Planalto da Serra Geral, o Rebordo do Planalto e a Depressão Periférica do estado do Rio Grande do Sul Muller Filho (1970), distando cerca de $270 \mathrm{~km}$ a Oeste da capital Porto Alegre. A figura 2 ilustra o mapa geológico associado-se as linhas de vôo executadas.

No presente trabalho para descrever o comportamento da variável urânio foram estimados os valores da média, do desvio padrão e o Limite Inferior da média (L.i.) e o Limite superior da média (L.s.) para $\alpha=0,05$ a partir da biblioteca Basic Statistical Analysis Methods/Basic Statistics/Tables do programa Statistica. 7.1 (Statsoft 2005).

Para descrever o comportamento espacial da variável, os dados foram ajustados a modelos polinomiais em função dos Valores de referências UTM, seguindose as direções Oeste-Leste e UTM Sul-Norte. Para o procedimento de ajuste polinomial foi empregada a biblioteca Advanced Linear/Nonlinear Models/ General Regression Models.7.1.

Para estimar o comportamento da variável urânio em função das diferentes formações geológicas foram retiradas amostras das partes mais centrais de cada formação, de forma proporcional aos seus tamanhos relativos, em um total de 25.806 observações.

Os valores amostrados foram submetidos à análise de variância dos teores de urânio em função das formações geológicas, posteriormente as médias de cada formação foram comparadas através do Teste de Tukey, tais procedimentos foram desenvolvidos através da biblioteca Basic Statistical Analysis Methods/ANOVA.

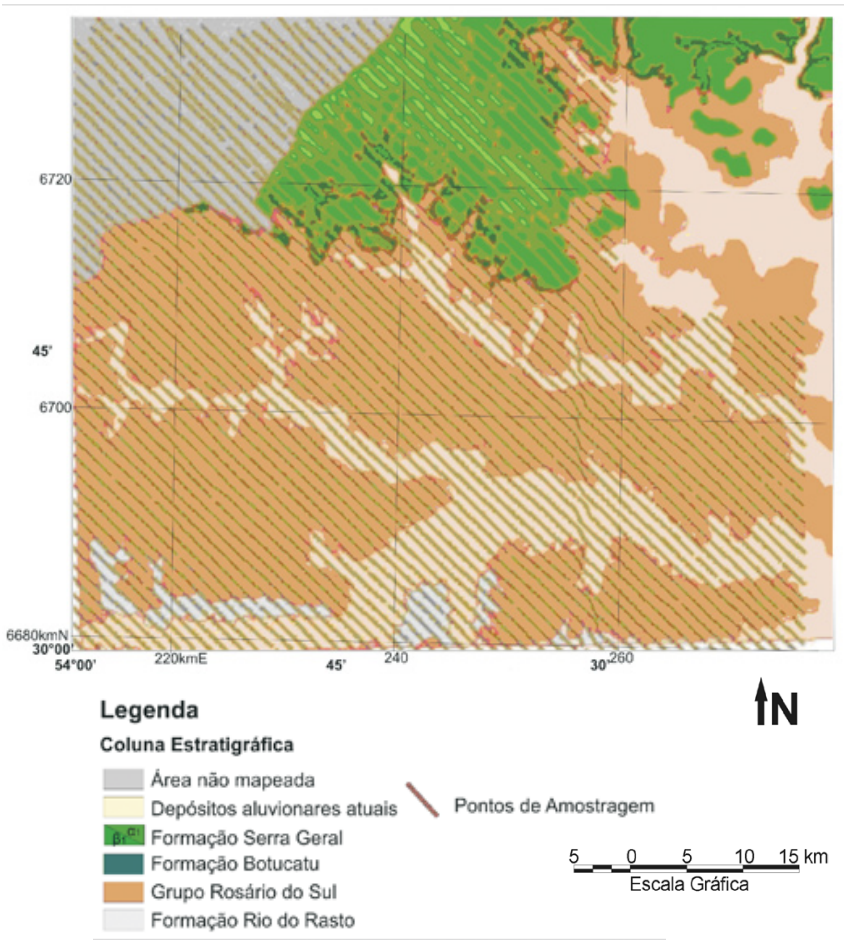

Figura 2 - Mapa geológico da área de estudo sobreposta pelas linhas de vôo.

No mapa geológico, representado na figura 1, descreveram-se sucintamente as principais características das litologias aflorantes, descritas no tabela 2.

Tabela 2 - Coluna estratigráfica simplificada da região em estudo de Santa Maria/RS. Fonte: Favilla \& Caldasso (1998), CPRM (2008).

\begin{tabular}{|c|c|c|c|}
\hline Cor & Código & Origem & Composição \\
\hline Branco & Qf4 & $\begin{array}{l}\text { Cenozóico, } \\
\text { Neógeno, } \\
\text { Quaternário }\end{array}$ & $\begin{array}{l}\text { Depósitos aluvionares atuais - cascalhos, areias grossas e finas e sedimentos } \\
\text { silticos-argilosos, inconsolidados que preenchem calhas de rios e suas planícies } \\
\text { de inundação. }\end{array}$ \\
\hline Verde médio & $\mathrm{Ksg} \beta_{1}$ & $\begin{array}{l}\text { Mesozóico, } \\
\text { Cretáceo. }\end{array}$ & $\begin{array}{l}\text { Formação Serra Geral - efusivas toleíticas básico-intermediárias e ácidas, } \\
\text { intercalando na base arenitos eólicos intertraps e intrusões e derrames picríticos } \\
\text { tipo Gravataí, sucedidos por basaltos tipo Gramado }\left(\beta_{1}\right.\end{array}$ \\
\hline Verde Claro & $\operatorname{Ksg} \alpha_{1}$ & $\begin{array}{l}\text { Mesozóico, } \\
\text { Cretáceo. }\end{array}$ & $\begin{array}{l}\text { Formação Serra Geral - efusivas toleíticas básico-intermediárias e ácidas, } \\
\text { intercalando na base arenitos eólicos intertraps, interdigitando superiormente } \\
\text { vulcanicas ácidas dotipo Palmas/Caxias }\left(\alpha_{1}\right) \text {. }\end{array}$ \\
\hline Verde escuro & $\mathrm{JKb}$ & $\begin{array}{l}\text { Mesozóico, } \\
\text { Jurássico. }\end{array}$ & $\begin{array}{l}\text { Formação Botucatu - Arenitos finos a médios, róseo-avermelhados, bem } \\
\text { selecionados, bimodais, com estratificações cruzadas tangenciaiseplano-paralela } \\
\text { de médio a grande porte. Paleoambiente eólico. }\end{array}$ \\
\hline Marron & TRrs & $\begin{array}{l}\text { Mesozóico, } \\
\text { Triássico. }\end{array}$ & $\begin{array}{l}\text { Grupo Rosário do Sul - arenitos arcosianos, siltitos e lamitos, com níveis } \\
\text { de conglomerados intraformacionais, preservados como blocos abatidos } \\
\text { em estruturas do tipo graben, arenitos avermelhados finos a médios com } \\
\text { estratificação paralela e cruzada acanalada. } \\
\text { Paleoambiente flúvio-eólico. }\end{array}$ \\
\hline Azul & Prr & $\begin{array}{l}\text { Paleozóico, } \\
\text { Permiano. }\end{array}$ & $\begin{array}{l}\text { Formação Rio do Rastro - arenitos finos, bem selecionados, lenticulares, } \\
\text { argilitos e siltitos esverdeados, bordos ou avermelhados, com laminações } \\
\text { paralelas e cruzadas acanaladas. }\end{array}$ \\
\hline Preto & $\mathrm{Zu}$ & Zona urbana & $\begin{array}{l}\text { Em Santa Maria, sedimentos Triássicos do Grupo Rosário do Sul e em São } \\
\text { Martinho da Serra, rochas vulcânicas }\end{array}$ \\
\hline
\end{tabular}


RESULTADOS As observações das concentrações de urânio apresentaram um valor médio de 1,56 ppm, com desvio padrão de 1,21 ppm e uma amplitude de variação entre zero a $8,98 \mathrm{ppm}$, sendo que o valor mais freqüente encontrado foi zero, fato que de ter distorcido as estimativas do valor da média e do desvio padrão. Este fato talvez justifique o valor elevado do coeficiente de variação $77,28 \%$ em torno da média Pereira (inédito) aplicandose o Teste de Kolmogorov- Smirnov com $\mathrm{P}<0,01$.

No histograma de freqüência da variável urânio figura 3, nota-se que a distribuição empírica da variável mostrou-se assimétrica à direita, apresentando um coeficiente de assimetria de 1,6, e levemente platicúrtica, com um coeficiente de curtose $\equiv 3$.

A variável urânio quando analisada em relação às coordenadas geográficas UTM apresenta uma dependência espacial. Expressa através do seguinte modelo polinomial de segundo grau.

$U=3913085-0,3556$. (UTM_O_L)- 2,9.10-8. (UTM $O L^{2}-1,1581$. (UTM_S N ) $\overline{-} 8, \overline{5} \cdot 10^{-8}\left(U T M \_S \_N\right)^{2} \mp$ $5, \overline{5}^{-8} \cdot\left(U T M \_O{ }_{-}{ }^{*} \cdot \overline{U T M} \bar{M}_{-} S_{-} N\right)$

A expressão gráfica do modelo citado pode ser visualizada na figura 4 , indicando um relacionamento espacial entre a variável urânio em relação a sua distribuição espacial no terreno. Percebe-se que na região do Planalto da Serra Geral de constituição vulcânica os valores de urânio são mais elevados enquanto na área da Depressão Periférica os valores são bem mais baixos associados as formações (Rio do Rasto, Grupo Rosário do Sul e Depósitos aluviais atuais).

As médias e os desvios padrões das concentrações de urânio estimadas para cada formação geológica estão apresentados no tabela 3.

As comparações entre as médias evidenciam que existe diferença significativa entre as médias de concentração da variável urânio nas várias formações geológicas, com exceção das formações Formação Rio do Rasto e Grupo Rosário do Sul, ambas constituídas por rochas sedimentares clásticas.

As relações entre as médias, com seus intervalos de confiança para $\alpha=0,05$, encontram-se apresen-

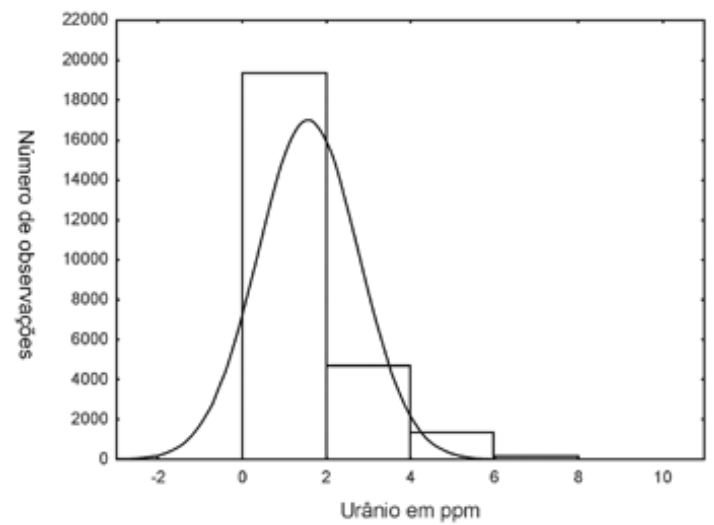

Figura 3 - Histograma de freqüência da variável urânio expressa em ppm.

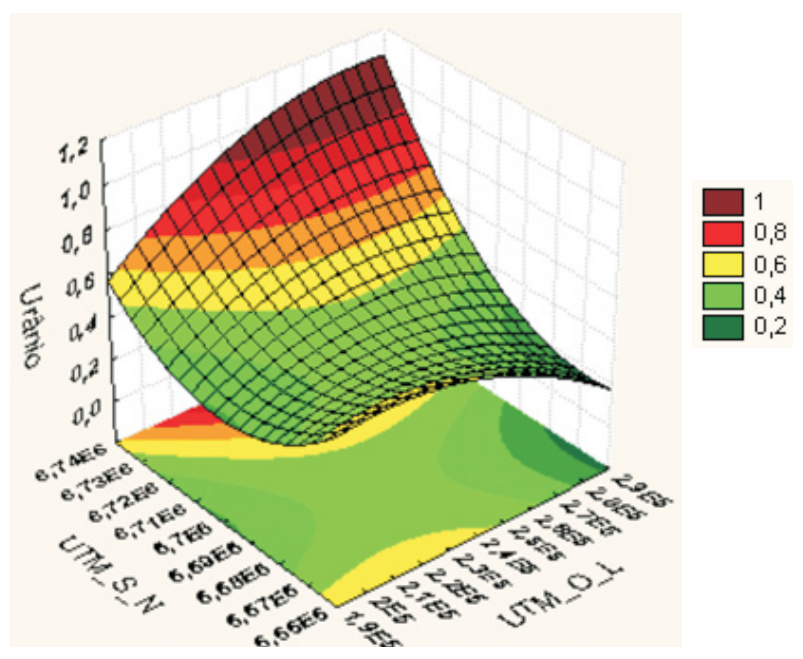

Figura 4 - Comportamento espacial da variável urânio, em ppm, em função das coordenadas UTM.

tadas nas diferentes formações geológicas aflorantes e podem ser vistas na figura 5 .

Da tabela 3 pode-se observar que apenas as

Tabela 3 - Concentrações da variável urânio avaliadas nas formações geológicas e zona urbana estudadas. (Informa-se que esta tabela não foi executado seguindo a coluna estratigráfica).

\begin{tabular}{l|c|c|c|c|c}
\hline $\begin{array}{l}\text { Identificação/ } \\
\text { Unidade Geológica }\end{array}$ & $\begin{array}{c}\text { Teor médio de } \\
\text { Urânio }\end{array}$ & $\begin{array}{c}\text { Erro padrão da } \\
\text { estimativa }\end{array}$ & $\begin{array}{c}\text { Limite Inferior } \\
\text { IC 95\% }\end{array}$ & $\begin{array}{c}\text { Limite } \\
\text { Superior } \\
\text { IC 95\% }\end{array}$ & $\begin{array}{c}\text { Tamanho da } \\
\text { amostra }\end{array}$ \\
\hline 1 Formação Rio do Rastro & $0,9484 \mathrm{a}$ & 0,0274 & 0,8947 & 1,0021 & 939 \\
\hline 2 Depósitos aluvionares atuais & $1,2022 \mathrm{~b}$ & 0,0167 & 1,1695 & 1,2349 & 2528 \\
\hline 3 Grupo Rosário do Sul & $1,1865 \mathrm{a}$ & 0,0106 & 1,1658 & 1,2073 & 6289 \\
\hline 4 Zona urbana & $2,3638 \mathrm{c}$ & 0,1122 & 2,1439 & 2,5836 & 56 \\
\hline 5 Formação Serra Geral $\left(\alpha_{1}\right)$ ácidas & $1,9811 \mathrm{~d}$ & 0,0330 & 1,9165 & 2,0458 & 648 \\
\hline 6 Formação Serra Geral $\left(\beta_{1}\right)$ básicas & $3,7581 \mathrm{e}$ & 0,0309 & 3,6976 & 3,8186 & 740 \\
\hline 7 Formação Botucatu & $3,4104 \mathrm{f}$ & 0,0674 & 3,2782 & 3,5425 & 155 \\
\hline
\end{tabular}

Obs. As médias seguidas de letras minúsculas diferem estatisticamente, $p<0,01$. 
médias da Formação Rio do Rasto e do Grupo Rosário do Sul não diferem, as outras diferem estatisticamente para uma $(P<0,05)$.

DISCUSSÃO Diversas pesquisas anteriores podem subsidiar a discussão dos resultados obtidos neste trabalho relativos às concentrações e/ou dispersão do urânio em rochas, dentre eles: Hawkes e Webb (1965), Mason (1966), Wedepohl (1969), Gamerman (1979), Bidone (1980), Khalaf (1988), Rocha (1992), Silvério da Silva (1997), Silvério da Silva \& Menegotto (2005), Silvério da Silva et al. (2006), Strieder \& Heemann (2006).

De acordo com Hawkes e Webb (1965) o urânio ocorre como mineral primário associado às estruturas cristalinas de zircão $\left(\mathrm{ZrSiO}_{4}\right.$ estável, podendo conter $\mathrm{U}_{3} \mathrm{O}_{8} \geq 1,5 \%$ incluído de acordo com Betejtin 1977), apatita $\mathrm{Ca}_{5}(\mathrm{~F}, \mathrm{Cl}, \mathrm{OH})^{-}$. $\left(\mathrm{PO}_{4}\right)_{3}$ (moderadamente estável) e na allanita $=$ ortita $(\mathrm{Ca}, \mathrm{Ce})_{2} .(\mathrm{Al}, \mathrm{Fe})_{3}\left\{\mathrm{Si}_{2} \mathrm{O}_{7}\right\}$. $\left\{\mathrm{SiO}_{4}\right\}$ O. $\{\mathrm{O}, \mathrm{OH}\}$ instável). A uraninita ou pichblenda $\left(\mathrm{UO}_{2}\right)$ ocorre como um constituinte primário de rochas graníticas e pegmatitos, e também como mineral secundário, associado aos minérios de prata, chumbo e cobre de Jonanngeogenstadt, Marienberg e Schneeberg, na Saxônia Dana \& Hurlbut (1978).

A mobilidade de um elemento varia com o tipo de mineral hospedeiro:

$\mathrm{O} \mathrm{U}^{4+}$ presente nos silicatos primários como ultratraço no zircão $\left(\mathrm{ZrSiO}_{4}\right)$, como traço na torita (Th$\mathrm{SiO}_{4}$ ) e como elemento varietal na uranotorita (UTh$\mathrm{SiO}_{4}$ ) é insolúvel como o Th (ambos têm mesmo raio iônico e mesma valência). Entretanto, o U pode ser lixiviado como $\mathrm{U}^{6+}$ (Uranila), o que não ocorre com o tório. Entretanto a solubilidade do U é tanto maior quanto maior for o seu teor no mineral - assim, o U da Uranotorita é mais facilmente lixiviado do que o da torita e esta mais que o do zircão.

Torianita $\left(\mathrm{ThO}_{2}\right)$ e Uraninita $\left(\mathrm{UO}_{2}\right)$ formam uma série isomorfa (minerais do sistema cúbico). A liberação do U oxidado da série faz com que o Th recristalize como Torianita, que é um dos minerais mais estáveis no ciclo exógeno.

Hawkes e Webb (1965) consideraram os depósitos minerais primários de urânio na forma de uraninita (intermediário entre $\mathrm{UO}_{2}$ e $\mathrm{UO}_{3}$ apud Betjtin, um óxido complexo de urânio, instável, a presença de $\mathrm{U}^{6+}$ deve-se, provavelmente ao processo de oxidação). Seus minerais secundários são carbonatos complexos, fosfatos e vanadatos. As fases aquosas mais importantes são $\left(\mathrm{UO}_{2}\right)^{2+} \mathrm{e}\left(\mathrm{UO}_{2}\right)\left(\mathrm{CO}_{3}\right)_{3}^{4-}$.

Comparando-se os resultados obtidos para as rochas sedimentares clásticas apresentadas no tabela 3 e na figura 5, as concentrações de urânio na Formação Rio do Rasto, nos Depósitos Aluvionares arenosos e, nas rochas sedimentares areno-argilosas pertencentes ao Grupo Rosário do Sul, a faixa de variação da concentração de urânio foi baixa entre 1,17 a 1,21 ppm e valor médio $1,19 \mathrm{ppm}$. Por outro lado às concentrações médias mais elevadas de urânio 3,41 ppm associadas aos arenitos quartzosos, pertencentes à Formação Botucatu, bem selecionados, de granulometria média a fina, de pa-

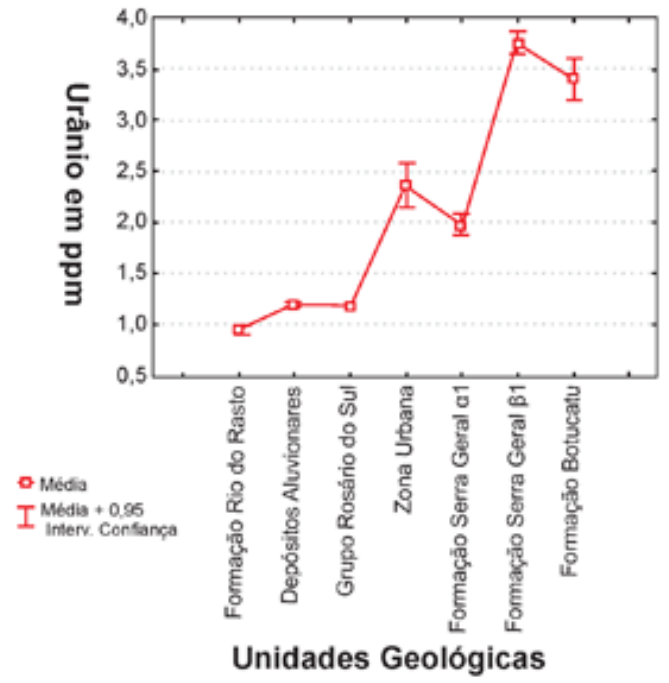

Figura 5 - Gráfico da dispersão das médias de concentração da variável urânio em (ppm) para as diferentes formações geológicas e zona urbana de São Martinho da Serra.

leoambiente eólico. Estes arenitos contendo cimentação na forma de películas de óxido-hidróxidos de $\mathrm{Fe} / \mathrm{Mn}$, de coloração avermelhados formam red beds e ainda apresentam argilominerais cauliníticos e illitas os quais poderiam adsorver parte do urânio Gamerman (1979).

Este comportamento anômalo apresentado de maior concentração média de urânio na Formação Botucatu (Fig. 5), podem relacionar-se com aspectos paleoclimáticos, de ambiente eólico e/ou a coprecipitação de urânio associado em películas de óxido/hidróxidos de $\mathrm{Fe} / \mathrm{Mn}$ associados aos processos diagenéticos. Baseado em Hawkes e Webb (1965) o urânio é extremamente móvel sob condições alcalinas e oxidantes, limitada pelo Eh (potencial de oxi-redução) de redução do complexo de uranila $\mathrm{UO}_{2}^{+2}$. Salientaram que devido à alta mobilidade do urânio no solo, este pode ser lixiviado por reagentes fracos fato que ajudaria na localização de áreas alvo, nas campanhas de prospecção econômica de urânio (Holland et al. 1957 e 1958).

Khalaf (1988) estudando a petrografia e a diâgenese de silcretes (concreções silicosas) no Kuwait, Golfo Arábico, salientou a importância de alguns calcretes (concreções calcárias) associados em camadas vermelhas de red beds que podem apresentar fontes econômicas de urânio, alumínio e de sulfatos. Silvério da Silva (1997) e Silvério da Silva \& Menegotto (2005) estudaram as concentrações de urânio em diversas rochas sedimentares de Idade Mesozóica da região de Santa Maria e suas concreções em (silcretes e calcretes) com uso de Inductively Coupled Plasma/ Mass Spectrometer (ICP/MS). As camadas de red beds foram formadas durante a formação dos paleoambientes flúvio-eólico durante a deposição do Grupo Rosário do Sul, mais especificamente das camadas vermelhas siltoargilosas da Formação Santa Maria (Membro Alemoa). 
Também ocorreu durante a deposição dos arenitos eólicos da Formação Botucatu.

Ainda no estado do Rio Grande do Sul Heemann (1997) e, Strieder \& Heemann (2006) encontraram valores de urânio na faixa entre 0,8 a 1,6 ppm nos basaltos intergranulares pertencentes à Formação Serra Geral, enquanto para os basaltos glomeropórfiros um valor médio de 0,6 ppm. Para os dacitos (ácidos) encontraram um valor bem superior da ordem de 5,0 ppm. Estes autores ainda encontraram concentrações de 2,92 ppm para os arenitos pertencentes à Formação Botucatu e valores na faixa de 1,9 a $8,7 \mathrm{ppm}$ para os arenitos argilosos pertencentes à Formação Rosário do Sul (equivalente a Formação Pirambóia nos estados de São Paulo e no Paraná).

De acordo com Hawkes e Webb (1965) o urânio é um elemento litófilo e pode associar-se com V, As, $\mathrm{P}, \mathrm{Mo}, \mathrm{Se}, \mathrm{Pb}$ e $\mathrm{Cu}$ em depósitos sedimentares resultantes de intemperismo em ambientes desérticos. Seu clarke de concentração, isto é, sua concentração média nas rochas da crosta terrestre é de 0,0002 . Seu potencial iônico, isto é, a relação entre a carga elétrica e o seu raio iônico $(\mathrm{Z} / \mathrm{r}=4)$ é média para o $\mathrm{U}^{4+}$, sendo precipitado por hidrólise, seus íons estão associados com os grupos hidroxila das soluções aquosas. Estes autores apresentaram como concentração média de urânio em rochas sedimentares arenosas $0,45 \mathrm{ppm}, 4,1 \mathrm{ppm}$ em folhelhos e 1 ppm como valor médio em solos.

Drever (1997) apresentou valores médios de 2 ppm de urânio em arenitos, descreveu a importância de variações nas condições paleaombientais de oxi-redução nas águas subterrâneas em arenitos associadas aos depósitos de urânio do tipo Roll-front (avanço com o fluxo subterrâneo). O urânio ocorre com dois estados de valência $\mathrm{U}^{4+}$ e $\mathrm{U}^{6+}$. O processo de intemperismo das rochas converte o $\mathrm{U}^{4+}$ (insolúvel) por oxidação para o estado $\mathrm{U}^{6+}$, solúvel em água, na forma de complexos de uranila $\left(\mathrm{UO}_{2}\right)^{2+}$.

Bidone (1980) estudou vários índices relativos aos depósitos de urânio associados às rochas sedimentares e red beds na região norte ocidental da Bacia Neogênica de Roussillion na França, encontrando associações de urânio adsorvido/coprecipitado com películas de óxidos-hidróxidos em torno de partículas de grãos arenosos e/ou a fases de argilominerais.

De acordo com Rocha (1992) a província uranífera de Lagoa Real, localizada no centro-sul da Bahia contém diversas jazidas de urânio descobertas por levantamento aerogeofísico (radiométrico). O contexto geológico inclui um embasamento arqueano-proterozóico inferior, parte do Craton São Francisco. As mineralizações de urânio relacionam-se ás fácies de gnaisses albitizados do Complexo Lagoa Real (Proterozóico inferior). Estudos geomorfológicos preliminares revelaram dois contextos preferenciais para explicar as anomalias radiométricas encontradas: a zona de escarpa, onde se encontram todas as jazidas conhecidas; e o alto platô, com anomalias fracas e difusas. A jazida Laranjeiras é um bom exemplo de jazida de encosta. Ela é recoberta por um manto de alteração laterítico típico de ambi- entes tropicais. Os estudos geoquímicos mostram que o urânio lixiviado das mineralizações migra com elementos associados, em direção a jusante. A relação entre o urânio remobilizado e sua expressão radiométrica superficial foi estabelecida. As fases minerais secundárias, portadoras de urânio foram identificadas nos perfis de alteração. O urânio ocorre adsorvido aos produtos de alteração amorfos, particularmente nos oxihidróxidos de Ferro-Titânio e nos produtos argilosos ricos em ' $\mathrm{CE}$ ' (camadas expansivas Ilitas-Smectitas).

Silvério da Silva (1997) e Silvério da Silva \& Menegotto (2005) estudaram as concentrações de urânio em diversos materiais geológicos pertencentes ao Grupo Rosário do Sul, tais como: as concreções carbonáticas (calcretes) obtendo uma média de 2,6 ppm, e uma faixa de variação entre 0,8 a 10,0 ppm, em seis amostras. Já em rochas sedimentares silicosas, o valor médio obtido foi 4,9 ppm, com uma variação entre 1,8 a 14,0 ppm em dez amostras. Em crostas silicificadas o valor médio obtido foi de 3,8 ppm, com uma faixa de variação entre 1,9 a 8,7 ppm, concluindo que estes materiais não formaram barreiras efetivas na concentração de urânio.

Silvério da Silva et al. (2006) estudaram a concentração de urânio em águas subterrâneas de fontes/ nascentes, associadas às rochas ígneas da Formação Serra Geral e as arenosas da Formação Botucatu, na fronteira do Estado do Rio Grande do Sul com o Uruguai. Encontraram valores deste elemento abaixo do Limite de Quantificação do ICP/MS ( $<5$ ppt). Silvério da Silva \& Menegotto (2005) concluíram que alguns elementos traços apresentaram concentração relativa nos silcretes, em relação às rochas sedimentares onde estavam inseridos, especialmente U, W, Mo, Co e Ta nos estudos de balanço de massa realizados para a região de Santa Maria.

Desta forma buscando-se subsídios em trabalhos anteriores para explicar valores médios de concentração de urânio transformados pela técnica back-calibration para partes por milhão indicariam que; este elemento nos arenitos eólicos da Formação Botucatu poderia estar associado por adsorção/coprecipitação na formação de películas de óxido-hidróxidos em grãos de quartzo do arcabouço dos arenitos e/ou associados às fases dos argilominerais peliculares Gamerman (1979).

De acordo com Hawkes e Webb (1965) o teor médio de urânio em rochas ígneas é de 2,6 ppm, enquanto nas rochas ígneas félsicas, tais como os dacitos, os valores $(3,5 \mathrm{ppm})$ são bem superiores aos das rochas básicas $(0,8 \mathrm{ppm})$. Comparando-se estes valores com os obtidos nas rochas básico-ácidas da Formação Serra Geral o tipo $\left(\alpha_{1}\right)$, riólitos e granófiros apresentaram uma concentração média de 1,98 ppm no tabela 3 e figura 5, associado às características ácidas, seria comparado ao das rochas ígneas félsicas. Por outro lado os valores de urânio associados ás rochas básicas, basaltos, tipo $\left(\beta_{1}\right)$ $3,76 \mathrm{ppm}$ seriam comparados aos das rochas básicas. Estes valores de concentração, aparentemente anômalos, apresentaram um valor médio de concentração nas rochas ígneas básicas os quais poderiam estar relacionados com os arenitos interderrames, pertencentes à Formação Botucatu. Este fato deve contribuir para explicar 
a ocorrência de valores médios de concentração urânio mais elevados nas rochas vulcânicas básicas. Em função dos afloramentos de arenitos interderrames, estas ocorrências foram identificadas por Silvério da Silva et $a l$. (inédito) em áreas vizinhas a área do estudo, localizadas a oeste no Município de Toropi. Informa-se ainda que os afloramentos de arenitos quando ocorrem são de dimensões não mapeáveis na escala de 1:250.000 (Favilla \& Caldasso 1998) apresentam às vezes áreas com dimensões de $200 \mathrm{~m}$ x $50 \mathrm{~m}$. Estes arenitos também ocorrem em subsuperfície e foram identificados em diversos poços tubulares em Toropi/Rio Grande do Sul em cadastro do Sistema de Informação de Águas Subterrâneas/SIAGAS (CPRM 2007). Assim acredita-se que os valores médios de urânio mais elevados nas rochas vulcânicas básicas do tipo $\left(\beta_{1}\right)$ estariam associados aos arenitos interderrames e/ou seus afloramentos no Rebordo da Serra Geral que ocorrem na região avaliada. No mapa geológico da CPRM (2008) também são citadas as ocorrências de arenitos intertrápicos associados as rochas básicas da Formação Serra Geral.

Pedron (2007) estudando os Neossolos Litólicos formados a partir de derrames de rochas ácidas obteve uma predominância da fração siltosa enquanto que os evoluídos de rochas básicas predominaram a fração argila. Estudos futuros enfocarão a Capacidade de Troca de Cátions e os argilominerais associados as concentrações de urânio. Estudos a serem detalhados em Litossolos Litólicos e seus produtos de alteração em relação as concentrações de urânio, deverão trazer novas faixas de concentrações em áreas não mineraliza- das, aplicando-se o método estatístico.

CONCLUSÕES 1 - O presente estudo mostrou que as concentrações de urânio ocorreram de forma distinta nas diferentes formações geológicas estudadas, podendo ser separadas em dois grupos (de rochas sedimentares clásticas constituídas principalmente por arenitos, pelitos da Formação Rio do Rasto (0,94 ppm), do Grupo Rosário do Sul (1,18 ppm) e os sedimentos inconsolidados aluvionares Holocênicos (1,20 ppm) tabela 3 .

Um segundo grupo, apresentando teores médios mais elevados de urânio em rochas ígneas vulcânicas ácidas $\left(\alpha_{1} 1,98 \mathrm{ppm}\right)$ e básicas $\left(\beta_{1} 3,76 \mathrm{ppm}\right)$, estas últimas associadas a arenitos intertrápicos da Formação Botucatu (3,41 ppm) os quais ocorrem no Rebordo do Planalto da Serra Geral e podem localmente, estarem mais enriquecidos neste elemento.

2- Os resultados obtidos evidenciaram a possibilidade de se distinguir diferentes unidades geológicas por meio de dados aerogeofísicos gamaspectrométricos pré-existentes. Estudos futuros poderão aprimorar o nível de conhecimento da faixa de variação da concentração de urânio em áreas não mineralizadas.

3- Que foi possível ajustar modelos polinomiais que descrevem a variabilidade espacial da concentração de urânio em função das coordenadas geográficas Universal Transversa de Mercator no terreno.

Agradecimentos Os autores agradecem as sugestões dos revisores da Revista Brasileira de Geociências e o apoio financeiro da FAPERGS.

\section{Referências}

Aarnisalo J. 1984. Image processing and Integration of Geophysical, LANDSAT and other data as a tool for Mineral Exploration and Glaciated Precambrian Terrain. In: International Symposium on Remote Sensing of Environmental, T. Conference, Remote Sensing for Exploration Geology, 3, Colorado, Anais, p. 107-127.

Almeida Filho R. \& Castelo Branco R.G. 1992. Location of Kimberlites using LANDSAT Thematic Mapper images and aerial photographs: the Redondão diatreme, Brazil. Intern. Journal Remote Sensing, 13(8):1449-1457.

Bastos R.O. 2002. Radiação Gama natural de distintos litotipos e a estimativa de dose a eles associada, em municípios do leste do estado de São Paulo. Dissertação de Mestrado, IG-UNICAMP, São Paulo, p.58.

Bidone E.D. 1980. Les índices d'uranium du Pliocene de la región nord occidentale du bassin neogene du Roussillion dans leur cadre sedimentologique. Thése Docteur-Ingénieur, France- Institut National Polytechnique de Lorraine-Nancy- France-INPL.

Betejtin A. 1977. Curso de Mineralogia. Moscou, editora Paz. 731p.

Buffon S.A. 2002. Integração de dados geofísicos e geológicos na avaliação ambiental e epidemiológica de radiações naturais (Radônio) no Escudo Sul-Riograndense (Rio Grande do Sul-Brasil). Dissertação de Mestrado.
PPGEM, UFRGS, p.150.

COMPANHIA DE PESQUISAS DE RECURSOS MINERAIS (CPRM), GEOLOGICAL SURVEY OF CANADÁ (GSC), PATERSON, GRANT \& WATSON LIMITE (PGW) 1997. Brazil Airborne Radiometric Mapping Project (BARMP). Technical Report and Survey Atlas, Ottawa, Canada.

COMPANHIA DE PESQUISAS DE RECURSOS MINERAIS (CPRM). 2007a. Catálago de projetos aerogeofísicos. Disponível em: http://www.cprm.gov.br/aero/ aero.htm. Acesso em 5/01/2007.

COMPANHIA DE PESQUISAS DE RECURSOS MINERAIS (CPRM) 2007b. Sistema de Informação de Águas Subterrâneas/SIAGAS. Disponível em http://www. cprm.gov.br/siagas. Acesso em 1/02/2007.

COMPANHIA DE PESQUISAS DE RECURSOS MINERAIS (CPRM). 2008. Geologia e Recursos Minerais do Estado do Rio Grande do Sul. Programa Geologia do Brasil. Integração, Atualização e Difusão de Dados de Geologia do Brasil. Mapas Geológicos Estaduais Escala de 1: 750.000, CD-ROM.

Cruz A.C.J.R. \& Remacre A. Z. 2001. Impacto de efeito suporte e do efeito informação sobre a recuperação de reservas. Revista da Escola de Minas, 54(2):137-142.

Drever J.I. 1997. The geochemistry of natural waters- Sur- 
face and groundwater environments. $3^{\text {a }}$ edition. University of Wyoming, 436p.

Dana J.D. \& Hulrbut C.JR. 1978. Manual de Mineralogia. Tradução para o português Rui Ribeiro Franco. Rio de Janeiro, Livros técnicos e científicos editora, 2 v., 643p.

Eliason P.T., Donavan T.J., Chaves JR. P.S. 1983. Integration of geologic, geochemical and geophysical data of the cement oil field, Oklahoma, using spatial array processing. Geophysics, 48(10):1305-1317.

Favilla C.A.C. \& Caldasso A.L.S. 1998. Mapeamento Gológico Integrado da Bacia Hidrográfica do Guaíba, (Pró-Guaiba) Folha de Santa Maria, SH. 22-V.C. Porto Alegre, Convênio CPRM/Governo do Estado do Rio Grande do Sul/METROPLAN, Escala de 1:250.000.

Gamerman N. 1979. Contribution a l'étude de la diagênese des grès: couleur rouge, argiles authigènes et induration. Formations d'Estrada Nova, De Rosário do Sul et de Botucatu (Brésil) et Buntsandstein des Vosges (France). Thése Docteur-Ingénieur, Memórie 59, Centre National de la Recherche Scientifique Université Louis Pasteur de Strasbourg Institut de Geólogie, p.121 et pranches XXI.

Green A.A. \& Craig M. 1984. Integrated analysis of image data for mineral exploration. In: International Symposium on Remote Sensing of Environment, Third Thematic Conference, Remote Sensing for Exploration Geology, Colorado Springs, Anais, p. 131-134.

Hawkes H.E. \& Webb J.S. 1965. Geochemistry in mineral exploration. A Harper international student reprint, 415p.

Heemann R. 1997. Geologia, controles e guias prospectivos para depósitos de ágata na região de Salto do Jacuí (RS). Dissertação de Mestrado, Escola de Engenharia, UFRGS, Porto Alegre, 107p.

Khalaf F.I. 1988. Petrography and diagenesis of Silcrete from Kuwait, Arabian Gulf. Journal of Sedimentary Petrology. 58(6):1014-1022.

Landim P.M.B. 2000. Análise Estatística de dados Geológicos Multivariados. UNESP/Campus Rio Claro. Laboratório de Geomatemática- DGA, IGCE, UNESP/Rio Claro, Texto Didático 03, 128p. Disponível em http:// www.rc.unesp.br/igce/aplicada/textodi.html. Acesso em 04/01/2007.

Mason B. 1966. Princípios de Geoquímica. 403p.

Miranda F.P., Fonseca L.E.N., Nunes K.C., Costa A., Almeida Filho R., Felgueira C.A. 1992. Integração digital de dados de sensoriamento remoto, aeromagnetometria e topografia na definição do arcabouço estrutural da região do Rio Uatumã (Bacia do Amazonas). In: SBG, Cong. Brasileiro de Geologia, 37, S. Paulo, Anais, 1:159-160.

Muller Filho I.L. 1970. Notas para o Estudo da Geomorfologia do Rio Grande do Sul, Brasil. UFSM, Publicação Especial no1, 34p.

Paradella W.R., Vitorello I., Lui C.C., Mattos J.T., Dutra L.V., Meneses P.R. 1990. Imagens do Satélite SPOT-1 em Mapeamento Geológico: um estudo comparativo com vários produtos de sensores no Vale do Rio Curaçá, Bahia. Revista Brasileira de Geociências; 20(1-4):282-292.

Pedron F. 2007. Mineralogia, morfologia e classificacão de saprolitos e neossolos derivados de rochas vulcânicas no Rio Grande do Sul. Tese de Doutoramento, Centro de Ciências Rurais, Univ. Federal Santa Maria-RS, 160p.
Pereira J.ES., Silvério da Silva J.L., Strieder A.J., Pires C.A.F. 2007. Análise Estatística da Concentração de Potássio obtida por Aerolevantamentos Geofísicos em Diferentes Formações Geológicas na Região de Santa Maria (RS). Rev. Pesquisas em Geociências, UFRGS, 34(2):99-107.

Pereira J.ES., Strieder A.J., Silvério da Silva J.L., Pires C.A.F. 2008. Estudo do campo magnético terrestre em função dos diferentes materiais geológicos da Região de Santa Maria (RS-Brasil). Revista Ciência e Natura, 30(1):111- 127.

Rocha E.B. 1992. Dispersão e redistribuição de urânio e acompanhadores em mineralizações uraniferas submetidas à alteração lateritizante: exemplo da jazida Laranjeiras. Província uranífera de Lagoa Real, Bahia. Tese de doutoramento, Instituto Geológico e Astronômico, USP/IGA, São Paulo, p.150.

Rolim S.B.A., Paradella W.R., Vasconcellos R.M., Azevedo M.L.V. 1993. Metodologia para sensores no vale do Rio Curaçá, Bahia. Revista Brasileira de Geociências, 20(14):282-292.

Silvério da Silva J.L. 1997. Estudo dos processos de silicificação e calcificação em rochas sedimentares Mesozóicas do Rio Grande do Sul, Brasil. Tese de Doutoramento, Instituto de Geociências, Universidade Federal do Rio Grande do Sul. Porto Alegre, 157p.

Silvério da Silva J.L. \& Menegotto E. 2002. Aspectos mineralógicos de silicificação em rochas sedimentares Mesozóicas no Rio Grande do Sul. Revista Brasileira de Geociências 32(3):317-326.

Silvério da Silva J. L. \& Menegotto E. 2005. Aspectos Geoquímicos de silicificações em rochas sedimentares no Rio Grande do Sul, Brasil. Pesquisas IG-UFRGS, 32(2): 29-40.

Silvério da Silva J.L., Camponogara I., Frantz L.C., Bessouat C., Guimarães M., Gamazo P., Failache L. 2006. Estudo da caracterização de áreas de recarga e descarga do SAG em Santana-Rivera e Quarai-Artigas. Estudo da vulnerabilidade na área de influência de Quaraí-Artigas. Projeto $N^{\circ} 10$, Fundo das Universidades, OEA/GEF. Relatório Final Julho de 2006. p. 195 e anexos. Disponível em http:/www.sg-guarani.org/fundo das universidades. Acessado em 10/05/2007.

STATSOFT INC. 2005. Statistica version 7.1, Series: $115 \mathrm{a}$. CD-Rom.

Strieder A.J. \& Heeman R. 2006. Structural constraints on Paraná basalt volcanism and their implications on agate geode mineralization (Salto do Jacuí, Rio Grande do Sul, Brazil). Revista Pesquisas em Geociências, Revista Pesquisas em Geociências, 33(1): 37-50.

Wedepohl K. H. 1969. Handbook of geochemistry. BerlinHeidelberg-New York, Springer-Verlang. Vol. 1, 402p.

Wilford J.R., Bierwirth P.N., Craig M.A. 1997. Application of airbone gamma-ray spectrometry in soil/regolith mapping and applied geomorphology. AGSO. Journal of Australian Geology \& Geophysics, 17(2):201-216.

Manuscrito ID 9430

Submetido em 02 de outubro de 2007 Aceito em 22 de setembro de 2008 Sistema eletrônico de submissão 